Article

\title{
Understanding the Relationship between User's Subjective Feeling and the Degree of Side Curvature in Smartphone
}

\author{
Yushin Lee ${ }^{1}$, Wonjoon Kim ${ }^{2, *}{ }^{\mathbb{C}}$, Joong Hee Lee ${ }^{3}$, Yong Min $\mathrm{Kim}^{3}$ and Myung Hwan Yun ${ }^{3, *}$ \\ 1 Institute of Engineering Research, Seoul National University, Seoul 08826, Korea; keynote1112@gmail.com \\ 2 Department of Industrial \& Management Engineering, Sungkyul University, Anyang 14097, Korea \\ 3 Department of Industrial Engineering \& Institute for Industrial System Innovation, \\ Seoul National University, Seoul 08826, Korea; jetishie@snu.ac.kr (J.H.L.); fides.ymkim@gmail.com (Y.M.K.) \\ * Correspondence: wjkim@sungkyul.ac.kr (W.K.); mhy@snu.ac.kr (M.H.Y.); Tel.: +82-31-467-8186 (W.K.)
}

Received: 17 April 2020; Accepted: 8 May 2020; Published: 10 May 2020

\begin{abstract}
To develop a flexible display, smartphones with edge screens with curved displays on both sides of the main screen have been used widely. Considering that small differences in the form of smartphones, such as length, width, and thickness, could affect user experience, the effects of the curvature of the edge screen should be identified. This study aimed to investigate the effects of the curvature of edge screens on subjective feelings of smartphone users and to find out the optimal curvature. In the experiment, four nonfunctional samples with different radii of curvature $(4 R / 6 R / 8 R / 10 R)$ were used as samples, and participants evaluated the five subjective feelings: grip/control comfort, front/side visibility, and stability of the samples with four usage patterns. Our results revealed that $8 \mathrm{R}$ is the optimal curvature for the edge screen based on subjective feelings in smartphone usage. Moreover, the effect of the curvature of the edge screen on grip comfort and control comfort varied according to the usage patterns. The results of this study can be applied to design of the curvature of edge screens in smartphones and it is expected that it will contribute to improvement of users' satisfaction.
\end{abstract}

Keywords: smartphone usability; edge screen; smartphone design; subjective evaluation

\section{Introduction}

Smartphones have played an essential role as communication devices [1]. People perceive a smartphone as a necessity in everyday life and for work because of its various functionalities, including Internet service [2]. The penetration rate of smartphones has exceeded $50 \%$ in many western countries, and more than $80 \%$ of mobile phone users use smartphones in South Korea [3]. Because smartphone penetration is increasing and the market is becoming saturated, companies are making great efforts to satisfy not only technological progress but also user's perceived emotion [4].

In order to gain a competitive edge over competitors in a highly competitive market, research has been actively undertaken to determine the relationship between various dimensions related to the design of smartphones, such as length, width, thickness, and weight, and the user's subjective feelings. Pereira et al. [5] studied the relationships between subjective fatigue ratings and the physical features of smartphones, including size, weight, shape, and material. Lee et al. [6] identified optimal reach zones for the back-side interaction on smartphones with different widths and lengths based on subjective discomfort and muscle activation data when various tasks were given. Sung et al. [7] investigated the touch performance of one-handed thumb interactions with iPhone 5S, 6 , and 6 Plus by measuring the tapping time, hit count, and thumb-tip and determined reachability issues for large 
smartphones. In addition, Chowdhury and Kanetkar [8] determined the preferred size of smartphones with hand anthropometry data and in terms of smartphone handiness.

With the increase of information provided by smartphones and the development of technologies related to flexible displays, smartphones including curved displays are being launched. This type of display is called "edge", which means a curved display implemented on one or both sides [9]. In fact, the Galaxy Note Edge was launched as the first smartphone with an edge screen in 2014. Since then, the Galaxy Edge series has steadily been released. Moreover, other major manufacturers also started to launch smartphones with edge screens, such as the Xiaomi Note 2 and Vivo Xplay 6.

From the viewpoint that design variables such as size, shape, etc. are important characteristics that affect subjective satisfaction for users, the curvature of the side display can give a different feeling to the user compared to the flat display [10]. However, this issue has not been dealt with in previous studies. A few studies investigated the various facets of smartphones with curved screens. Ahn et al. [11] investigated the effect of the curvature of the screen and hand size of the user on the physical comfort of using curved smartphones. Kwon et al. [12], however, endeavored to determine the optimal curvature of the screen and thickness of the smartphone in terms of physical comfort using the muscular activities of the hand. However, they only focused on the curvature of the main screen. Yi et al. [13] studied the effect of display curvature and hand length on the usability of smartphones. The results showed that the perceived grip comfort in two situations, calling and texting, was the highest when the hand length was medium. In addition, the value of the perceived grip comfort of the curved display was lower than that of the flat display for all hand lengths. However, this study did not compare perceived grip comfort between curvature displays. Therefore, it is necessary to study the grip comfort according to the specifications of the curvature display on the smartphone side.

Grip/usage pattern and personal information such as gender, age, and size of hand should be considered to determine the effect of the physical dimension of mobile phones on user satisfaction. Previous studies related to convenience for handheld devices were performed mainly on the assumption that only a single hand is used [14]. This is because the size of most smartphones was small, and the use of a single hand was the main usage pattern. However, recently, as the size of smartphones has increased, it has become more common to use a smartphone with both hands. In addition, as the functions of smartphones become more diverse and the user interface gradually changes, various types of usage pattern have appeared. Lee et al. [6] classified the type of the grip on the smartphone into three front touches and two rear touches. Le et al. [15] classified the posture of using smartphones with one hand into three types: four-finger posture, small-finger posture, and clutch posture. Therefore, various usage patterns should be considered in determining the physical dimensions of smartphones.

In addition, as the screen size of smartphones is diverse, the demographic factors such as gender, age, and size of a user's hand becomes one of the most important factors affecting the convenience of using a smartphone. Zhang and his colleagues [16] confirmed that there are gender differences in metrics such as response time and hit rate for target selection on a smartphone with a large screen. Balakrishnan and Yeow [17] figured out the influence of hand breadth, thumb length, and thumb circumference when typing characters on mobile phones. Lin [18] analyzed the subjective fatigue according to the size of the smartphone by dividing the size of the human hand into three levels based on the hand length. Experimental results show that the small hand and medium hand have higher subjective fatigue as the size of the smartphone increases, and the opposite result is obtained in the case of large hands. These findings suggest that it is important to understand the relationship between demographic characteristics and the specifications of the smartphone when examining the subjective feel of smartphones.

Therefore, the purpose of this study is to understand the relationship between the curvature of the side display and the subjective feeling according to various usage patterns occurring in the smartphone and to compare the differences of subjective feeling. In addition, this study examines whether demographic variables such as gender and size of hand affect the usage patterns and design variables of smartphones. The remainder of this article is organized as follows. Section 2 describes information 
about subjects and samples and the research methods. Section 3 shows the results of the experiment. Finally, the discussions and conclusion of this study are given in Sections 4 and 5, respectively.

\section{Methods}

\subsection{Participants and Samples}

Only right-handed adults who owned smartphones were recruited. A total of 20 males and 20 females participated in the experiment, and their average age and period of smartphone usage were 34.15 years and 28.79 months, respectively. Demographic information for the participants is summarized in Table 1.

Table 1. Participants characteristic for the experiment.

\begin{tabular}{ccccccc}
\hline \multirow{2}{*}{ Category } & \multicolumn{3}{c}{ Male (n= 20) } & \multicolumn{3}{c}{ Female (n= 20) } \\
\cline { 2 - 7 } & Mean & SD & Range & Mean & SD & Range \\
\hline Age & 36.50 & 12.65 & $19-59$ & 31.80 & 12.42 & $21-56$ \\
PSU & 31.15 & 14.78 & $6-60$ & 26.32 & 10.62 & $3-48$ \\
HL & 18.39 & 0.85 & $16.82-20.00$ & 17.08 & 9.81 & $15.45-19.40$ \\
\hline \multicolumn{2}{l}{ Note. SD = standard deviation, PSU = period of smartphone usage (month), HL $=$ hand length $(\mathrm{cm})$}
\end{tabular}

Note. SD = standard deviation, $\mathrm{PSU}=$ period of smartphone usage $(\mathrm{month}), \mathrm{HL}=$ hand length $(\mathrm{cm})$.

Four nonfunctional mockups were created using 3-D printer as samples. The detailed description of the mockups is given in Figure 1. A total of four samples were composed of two parts: main display and curvature display on the side. First, the main display of all samples was a 5.5-inch flat display with a 16:9 aspect ratio. The curvature display on the right side had four different radii of curvatures ( $R, \mathrm{~mm}$ ): $4 \mathrm{R}, 6 \mathrm{R}, 8 \mathrm{R}$, and $10 \mathrm{R}$, and the weight of the sample was $115 \mathrm{~g}$ for $4 \mathrm{R}$ and $6 \mathrm{R}$, and $120 \mathrm{~g}$ for $8 \mathrm{R}$ and 10R, respectively. The sample lengths weights were slightly different from each other due to the curvature rate of the edge display.

(a)

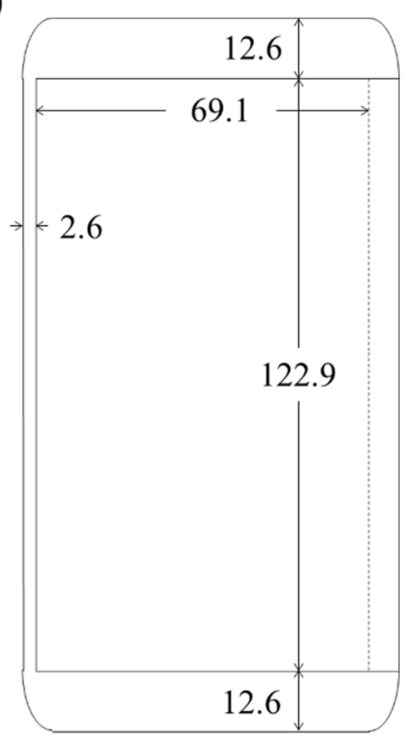

(b)
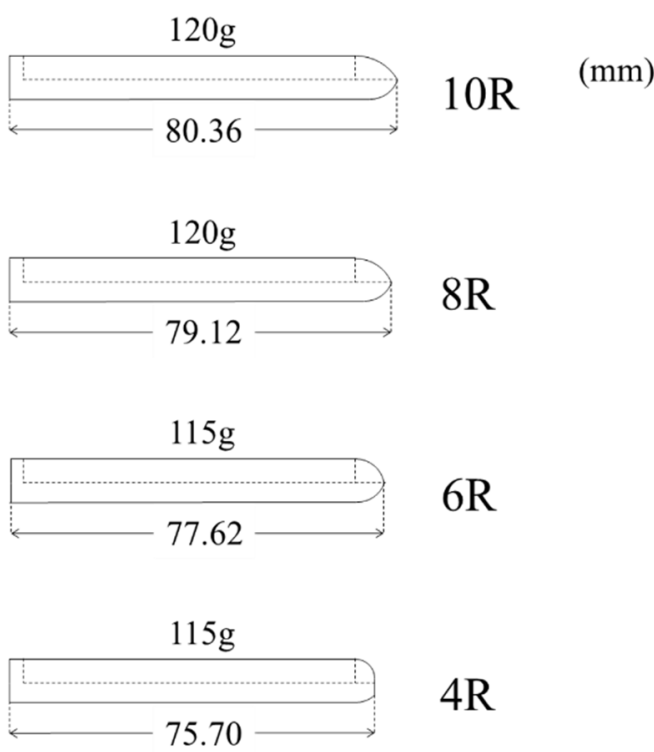

$8 \mathrm{R}$

$6 \mathrm{R}$

$4 \mathrm{R}$

Figure 1. Dimension of samples: (a) Plan view. (b) Section view.

\subsection{Usage Patterns and Tasks}

The selected usage patterns in this study are illustrated in Figure 2. First, three usage patterns were defined according to which hands were used for grip and control: grip with right hand and control with right thumb (Figure 2a), grip with left hand and control with right index finger (Figure 2b), 
and grip with both hands and control with both thumbs (Figure 2c). Considering one hand usage pattern varies from person to person, one more usage pattern was defined-a power grip with right hand and control with right thumb (Figure 2d). For these usage patterns, the subjects performed five control simulation tasks. The tasks were (a) touching on the main screen, (b) dragging on the main screen, (c) touching on the edge screen, (d) dragging vertically on the edge screen, and (e) laterally dragging between the main screen and edge screen. To be immersed in the experiment, a printed image of the main page of a Korean portal site attached to each sample with a web-surfing scenario was given for the subjects to perform all tasks naturally.

(a)

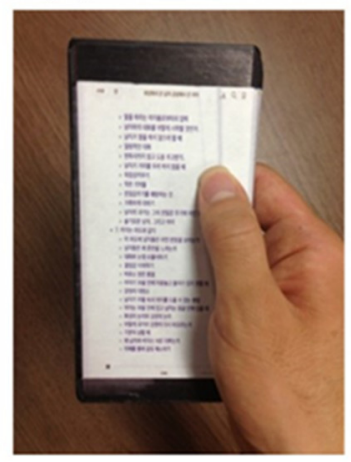

(c)

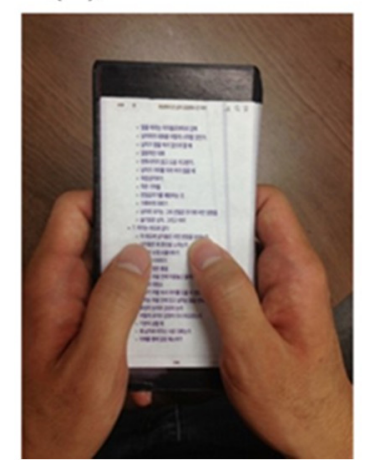

(b)

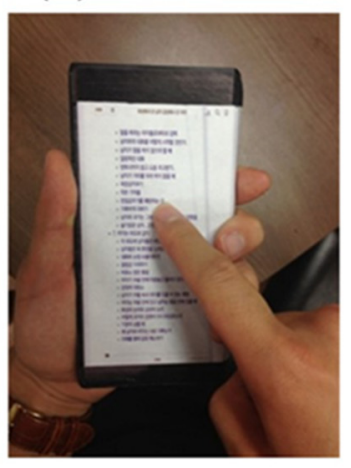

(d)

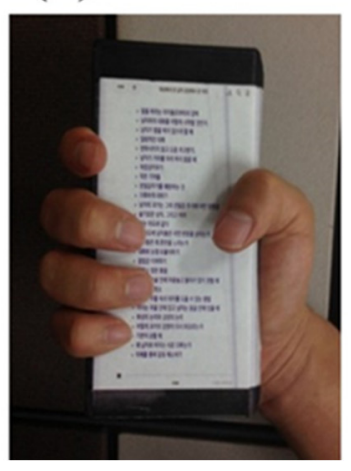

Figure 2. Illustration example of the four main usage patterns when using a smartphone. (a) Manipulate with the right thumb finger while gripping with the right hand. (b) Manipulate with the right index finger while gripping with the left hand. (c) Manipulate with both thumb while holding in both hands. (d) Manipulate with the right thumb finger while power grip.

\subsection{Subjective Evaluation}

To investigate the subjective feeling according to the side curvature and usage pattern in a smartphone, five questionnaire items were selected as shown in Table 2 based on interviews with experts in related fields. 
Table 2. Evaluated subjective feelings and their description.

\begin{tabular}{cl}
\hline Evaluation Factor & \multicolumn{1}{c}{ Question } \\
\hline Grip comfort & $\begin{array}{l}\text { Did you feel comfortable to grip without physical fatigue? } \\
\text { (1: completely uncomfortable, 4: neither uncomfortable nor comfortable, } \\
\text { 7: completely comfortable) }\end{array}$ \\
\hline \multirow{3}{*}{ Control comfort } & $\begin{array}{l}\text { Did you feel comfortable to control without awkwardness? } \\
\text { (1: completely uncomfortable, 4: neither uncomfortable nor comfortable, } \\
\text { 7: completely comfortable) }\end{array}$ \\
\hline Stability & $\begin{array}{l}\text { Did you feel a sense of stability without the worry of dropping? } \\
\text { (1: completely unstable, 4: neither unstable nor stable, 7: completely stable) }\end{array}$ \\
\hline \multirow{3}{*}{ Front visibility } & $\begin{array}{l}\text { Was the icons and texts on the edge screen visible when you look at from the } \\
\text { in front? } \\
\text { (1: completely invisible, 4: neither invisible nor visible, 7: completely visible) }\end{array}$ \\
\hline \multirow{2}{*}{ Side visibility } & $\begin{array}{l}\text { Was the icons and texts on the edge screen visible when you look at from } \\
\text { the side? } \\
\text { (1: completely invisible, 4: neither invisible nor visible, } 7: \text { completely visible) }\end{array}$ \\
\hline
\end{tabular}

In the experiment, they assessed their subjective feelings toward the samples in terms of which edge screen curvatures were different after performing given control simulation tasks with four different types of usage pattern. Front and side visibility were evaluated only with usage patten (d).

In summary, two mixed factorial designs were used (Figure 3). First, a four way (between subjects: 2 [Hand length] $\times 2$ [Gender], within subjects: 4 [Curvature rate of edge screen] $\times 4$ [Usage pattern]) mixed factorial design was applied to identify the effects of four factors on grip/control comfort and stability. Second, a three way (between subjects: 2 [Hand length] $\times 2$ [Gender], within subjects: 4 [Curvature rate of edge screen]) mixed factorial design was conducted to capture the effects of three factors on front and side visibility.

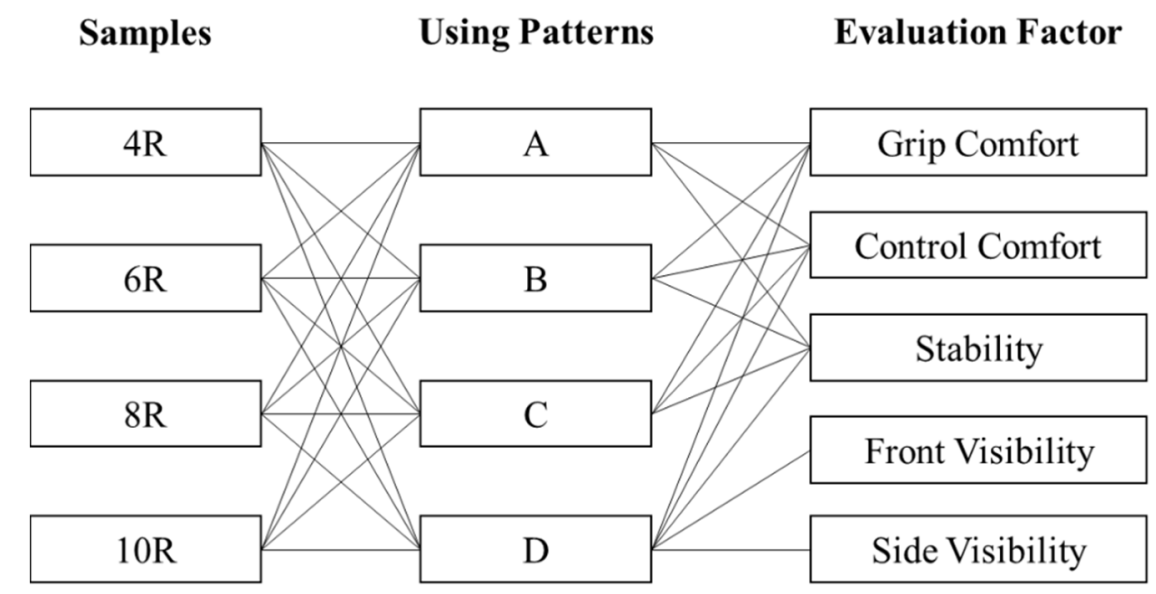

Figure 3. Experiment design of the study.

With reference to previous studies that measured the subjective feeling of users through a questionnaire [19-22], all subjective ratings in this study were evaluated using a 7-point Likert scale. To neglect the order effect, the samples were given in a randomized order. It took approximately $2 \mathrm{~h}$ per subject, including break time. Every subject was given written consent and agreed to participate in the experiment and receive financial compensation for the participation. This study was approved by the research ethics committee of Seoul National University (SNUIRB NO. 1412/001-017) and was conducted according to the guidelines laid down in the Declaration of Helsinki. 


\subsection{Statistical Analysis}

Two mixed factorial analyses of variance (ANOVA) were conducted because the study design was different according to the evaluated subjective feelings. Four-way (two between subjects factors and two within subjects factors) ANOVA was performed for the analysis of grip/control comfort and stability. In the case of front and side visibility, three-way (two between subjects factor and one within subjects factor) ANOVA was conducted.

The subjective ratings for which interaction effects were statistically significant were analyzed using a one-way ANOVA for each usage pattern. Post hoc analyses were followed using Duncan's test. All statistical analyses were conducted using IBM SPSS Statistics Version 24 (IBM Corp., Armonk, NY, United States).

\section{Results}

\subsection{Overall Demographic Results}

The results of descriptive statistics for the evaluation factor of each sample and usage pattern are shown in Table 3. The results of ANOVA showed that gender and hand size had no statistically significant effects on subjective feelings (Table 4).

Table 3. Results of descriptive statistics for the experiment.

\begin{tabular}{|c|c|c|c|c|c|c|}
\hline $\begin{array}{c}\text { Evaluation } \\
\text { Factor }\end{array}$ & $\begin{array}{c}\text { Samples \& Using } \\
\text { Pattern }\end{array}$ & $\mathbf{N}$ & $\min$ & Max & $\mathbf{M}$ & SD \\
\hline \multirow{8}{*}{$\begin{array}{l}\text { Grip } \\
\text { Comfort }\end{array}$} & Sample 4R & 160 & 1 & 7 & 4.656 & 1.423 \\
\hline & Sample 6R & 160 & 2 & 7 & 4.800 & 1.248 \\
\hline & Sample 8R & 160 & 1 & 7 & 4.906 & 1.302 \\
\hline & Sample 10R & 160 & 1 & 7 & 4.644 & 1.384 \\
\hline & Pattern (a) & 160 & 1 & 7 & 4.662 & 1.391 \\
\hline & Pattern (b) & 160 & 2 & 7 & 4.844 & 1.168 \\
\hline & Pattern (c) & 160 & 1 & 7 & 4.869 & 1.328 \\
\hline & Pattern (d) & 160 & 1 & 7 & 4.631 & 1.461 \\
\hline \multirow{8}{*}{$\begin{array}{l}\text { Control } \\
\text { Comfort }\end{array}$} & Sample 4R & 160 & 1 & 7 & 4.031 & 1.627 \\
\hline & Sample 6R & 160 & 1 & 7 & 4.331 & 1.426 \\
\hline & Sample 8R & 160 & 1 & 7 & 4.725 & 1.436 \\
\hline & Sample 10R & 160 & 1 & 7 & 4.606 & 1.401 \\
\hline & Pattern (a) & 160 & 1 & 7 & 4.344 & 1.475 \\
\hline & Pattern (b) & 160 & 1 & 7 & 4.531 & 1.479 \\
\hline & Pattern (c) & 160 & 1 & 7 & 4.450 & 1.529 \\
\hline & Pattern (d) & 160 & 1 & 7 & 4.369 & 1.507 \\
\hline \multirow{8}{*}{ Stability } & Sample 4R & 160 & 1 & 7 & 4.906 & 1.354 \\
\hline & Sample $6 R$ & 160 & 1 & 7 & 5.000 & 1.234 \\
\hline & Sample 8R & 160 & 1 & 7 & 5.038 & 1.213 \\
\hline & Sample 10R & 160 & 2 & 7 & 4.806 & 1.306 \\
\hline & Pattern (a) & 160 & 1 & 7 & 4.900 & 1.275 \\
\hline & Pattern (b) & 160 & 2 & 7 & 4.975 & 1.197 \\
\hline & Pattern (c) & 160 & 1 & 7 & 5.144 & 1.202 \\
\hline & Pattern (d) & 160 & 1 & 7 & 4.731 & 1.404 \\
\hline \multirow{4}{*}{$\begin{array}{c}\text { Front } \\
\text { Visibility }\end{array}$} & Sample 4R & 40 & 1 & 7 & 3.600 & 1.446 \\
\hline & Sample 6R & 40 & 3 & 7 & 4.375 & 1.254 \\
\hline & Sample 8R & 40 & 4 & 7 & 5.800 & 1.091 \\
\hline & Sample 10R & 40 & 3 & 7 & 6.050 & 1.037 \\
\hline \multirow{4}{*}{$\begin{array}{c}\text { Side } \\
\text { Visibility }\end{array}$} & Sample 4R & 40 & 1 & 7 & 4.900 & 1.411 \\
\hline & Sample 6R & 40 & 1 & 7 & 5.125 & 1.381 \\
\hline & Sample 8R & 40 & 1 & 7 & 5.375 & 1.409 \\
\hline & Sample 10R & 40 & 1 & 7 & 5.400 & 1.446 \\
\hline
\end{tabular}


Table 4. Test result of between subject effects (based on the results of two mixed ANOVAs).

\begin{tabular}{cccccccc}
\hline $\begin{array}{c}\text { Evaluation } \\
\text { Factor }\end{array}$ & Source & $\begin{array}{c}\text { Sum of } \\
\text { Squares } \\
\text { Type III }\end{array}$ & df & $\begin{array}{c}\text { Mean } \\
\text { Square }\end{array}$ & $\boldsymbol{F}$ & $p$ & $\eta_{p}^{2}$ \\
\hline \multirow{2}{*}{ Grip } & Gender & 3.525 & 1 & 3.525 & 0.418 & 0.522 & 0.011 \\
Comfort & Hand Type & 6.500 & 1 & 6.500 & 0.770 & 0.386 & 0.021 \\
& Gender $\times$ Hand Type & 11.157 & 1 & 11.157 & 1.321 & 0.258 & 0.035 \\
\hline \multirow{2}{*}{ Control } & Gender & 0.000 & 1 & 0.000 & 0.000 & 0.995 & 0.000 \\
Comfort & Hand Type & 12.238 & 1 & 12.238 & 1.101 & 0.301 & 0.030 \\
& Gender $\times$ Hand Type & 2.438 & 1 & 2.438 & 0.219 & 0.642 & 0.006 \\
\hline \multirow{2}{*}{ Stability } & Gender & 0.156 & 1 & 0.156 & 0.019 & 0.892 & 0.001 \\
& Hand Type & 0.306 & 1 & 0.306 & 0.036 & 0.850 & 0.001 \\
& Gender $\times$ Hand Type & 6.602 & 1 & 6.602 & 0.785 & 0.382 & 0.021 \\
\hline \multirow{2}{*}{ Front } & Gender & 2.377 & 1 & 2.377 & 0.710 & 0.405 & 0.019 \\
Visibility & Hand Type & 8.327 & 1 & 8.327 & 2.488 & 0.123 & 0.065 \\
& Gender $\times$ Hand Type & 0.077 & 1 & 0.077 & 0.023 & 0.881 & 0.001 \\
\hline \multirow{2}{*}{ Side } & Gender & 0.127 & 1 & 0.127 & 0.029 & 0.867 & 0.001 \\
Visibility & Hand Type & 3.452 & 1 & 3.452 & 0.779 & 0.383 & 0.021 \\
& Gender $\times$ Hand Type & 0.827 & 1 & 0.827 & 0.187 & 0.668 & 0.005 \\
\hline
\end{tabular}

\subsection{Grip/Control Comfort}

Regarding grip comfort, the effects of curvature and usage pattern were not significant (Table 5). Comparing them descriptively, the sample with a curvature of $8 \mathrm{R}$ scored the highest, followed by $6 \mathrm{R}, 4 \mathrm{R}$, and $10 \mathrm{R}$ (Table 3 ). However, the interaction effect between curvature and usage pattern was significant: $F(9,360)=2.324, p=0.005$.

Table 5. Results of four-way mixed ANOVA for grip comfort (Test result of within subject effects).

\begin{tabular}{ccccccc}
\hline Source & $\begin{array}{c}\text { Sum of Squares } \\
\text { Type III }\end{array}$ & df & $\begin{array}{c}\text { Mean } \\
\text { Square }\end{array}$ & $\boldsymbol{F}$ & $p$ & $\eta_{p}^{2}$ \\
\hline Sample & 7.517 & 3 & 2.506 & 1.552 & 0.205 & 0.038 \\
Error (Sample) & 188.920 & 117 & 1.615 & & & \\
Pattern & 7.142 & 3 & 2.381 & 0.931 & 0.428 & 0.023 \\
Error (Pattern) & 299.295 & 117 & 2.558 & & & \\
Sample $\times$ Pattern & 20.914 & 9 & 2.324 & 2.666 & 0.005 & 0.064 \\
Error (Sample $\times$ Pattern) & 305.898 & 351 & 0.872 & & & \\
\hline
\end{tabular}

Because the grip comfort has an interaction effect between curvature and usage pattern, it was analyzed separately according to the samples and usage patterns (Table 6). In the case of samples, 10R showed a significant difference in grip comfort between the usage patterns: $F(3,159)=4.269$, $p=0.006$. Post hoc analysis showed two homogeneous subsets. The first subset comprised usage patterns of $(b)$, and (c) $\left(\mathrm{M}_{\mathrm{b}}=4.750, \mathrm{M}_{\mathrm{c}}=5.200\right)$, and the second subset comprised usage patterns of (a), (b), and (d) $\left(\mathrm{M}_{\mathrm{a}}=4.450, \mathrm{M}_{\mathrm{b}}=4.750, \mathrm{M}_{\mathrm{d}}=4.175\right)$. In the case of usage patterns, however, all patterns showed no significant differences in grip comfort between samples. 
Table 6. Results of one-way ANOVA for grip comfort by each sample and usage pattern.

\begin{tabular}{|c|c|c|c|c|c|c|c|}
\hline & Source & & $\begin{array}{c}\text { Sum of Squares } \\
\text { Type }\end{array}$ & df & $\begin{array}{l}\text { Mean } \\
\text { Square }\end{array}$ & $F$ & $p$ \\
\hline \multirow{12}{*}{ Sample } & \multirow{3}{*}{$4 \mathrm{R}$} & Between & 0.319 & 3 & 0.106 & 0.052 & 0.985 \\
\hline & & Within & 321.775 & 156 & 2.063 & & \\
\hline & & Total & 322.094 & 159 & & & \\
\hline & \multirow{3}{*}{$6 \mathrm{R}$} & Between & 2.150 & 3 & 0.717 & 0.455 & 0.714 \\
\hline & & Within & 245.450 & 156 & 1.573 & & \\
\hline & & Total & 247.600 & 159 & & & \\
\hline & \multirow{3}{*}{$8 \mathrm{R}$} & Between & 2.469 & 3 & 0.823 & 0.481 & 0.696 \\
\hline & & Within & 267.125 & 156 & 1.712 & & \\
\hline & & Total & 269.594 & 159 & & & \\
\hline & \multirow{3}{*}{$10 R$} & Between & 23.119 & 3 & 7.706 & 4.269 & 0.006 \\
\hline & & Within & 281.575 & 156 & 1.805 & & \\
\hline & & Total & 304.694 & 159 & & & \\
\hline \multirow{12}{*}{ Pattern } & \multirow{3}{*}{ (a) } & Between & 2.675 & 3 & 0.892 & 0.456 & 0.713 \\
\hline & & Within & 305.100 & 156 & 1.956 & & \\
\hline & & Total & 307.775 & 159 & & & \\
\hline & \multirow{3}{*}{ (b) } & Between & 5.319 & 3 & 1.773 & 1.306 & 0.275 \\
\hline & & Within & 211.775 & 156 & 1.358 & & \\
\hline & & Total & 217.094 & 159 & & & \\
\hline & \multirow{3}{*}{ (c) } & Between & 8.719 & 3 & 2.906 & 1.670 & 0.176 \\
\hline & & Within & 271.525 & 156 & 1.741 & & \\
\hline & & Total & 280.244 & 159 & & & \\
\hline & \multirow{3}{*}{ (d) } & Between & 11.719 & 3 & 3.906 & 1.861 & 0.139 \\
\hline & & Within & 327.525 & 156 & 2.100 & & \\
\hline & & Total & 339.244 & 159 & & & \\
\hline
\end{tabular}

For the control comfort, the effect of curvature was significant: $F(3,120)=7.590, p<0.001$ (Table 7). Post hoc analysis using Duncan's test showed three homogeneous subsets. The first subset comprised the samples with curvatures of $8 \mathrm{R}$ and $10 \mathrm{R}$. The second subset comprised the samples with curvatures of $6 R$ and $8 R$, and the last subset comprised the samples with curvatures of $4 R$ and $6 R$. Moreover, the interaction effect between curvature and usage pattern was significant: $F(9,360)=4.526, p<0.001$.

Table 7. Results of four-way mixed ANOVA for grip comfort (Test result of within subject effects).

\begin{tabular}{ccccccc}
\hline Source & $\begin{array}{c}\text { Sum of Squares } \\
\text { Type III }\end{array}$ & df & $\begin{array}{c}\text { Mean } \\
\text { Square }\end{array}$ & $\boldsymbol{F}$ & $p$ & $\eta_{p}^{2}$ \\
\hline Sample & 45.867 & 3 & 15.289 & 7.590 & 0.000 & 0.163 \\
Error (Sample) & 235.695 & 117 & 2.014 & & & \\
Pattern & 3.467 & 3 & 1.156 & 0.426 & 0.734 & 0.011 \\
Error (Pattern) & 317.095 & 117 & 2.710 & & & \\
Sample $\times$ Pattern & 42.239 & 9 & 4.693 & 4.526 & 0.000 & 0.104 \\
Error (Sample $\times$ Pattern) & 363.948 & 351 & 1.037 & & & \\
\hline
\end{tabular}

Because the control comfort has an interaction effect between curvature and usage pattern, it was analyzed separately according to the samples and usage patterns (Table 8). In the samples, 10R showed a significant difference in grip comfort between the usage patterns: $F(3,159)=4.550, p=0.004$. Post hoc analysis showed two homogeneous subsets. The first subset comprised usage patterns of (a), (c), and (d), and the second subset comprised curvatures of (b), and (c). 
Table 8. Results of one-way ANOVA for control comfort by each sample and usage pattern.

\begin{tabular}{|c|c|c|c|c|c|c|c|}
\hline & Source & & $\begin{array}{c}\text { Sum of } \\
\text { Squares } \\
\text { Type }\end{array}$ & df & $\begin{array}{l}\text { Mean } \\
\text { Square }\end{array}$ & $F$ & $p$ \\
\hline \multirow{12}{*}{ Sample } & \multirow{3}{*}{$4 \mathrm{R}$} & Between & 9.369 & 3 & 3.123 & 1.184 & 0.318 \\
\hline & & Within & 411.475 & 156 & 2.638 & & \\
\hline & & Total & 420.844 & 159 & & & \\
\hline & \multirow{3}{*}{$6 \mathrm{R}$} & Between & 4.469 & 3 & 1.490 & 0.729 & 0.536 \\
\hline & & Within & 318.975 & 156 & 2.045 & & \\
\hline & & Total & 323.444 & 159 & & & \\
\hline & \multirow{3}{*}{$8 \mathrm{R}$} & Between & 6.750 & 3 & 2.250 & 1.093 & 0.354 \\
\hline & & Within & 321.150 & 156 & 2.059 & & \\
\hline & & Total & 327.900 & 159 & & & \\
\hline & \multirow{3}{*}{$10 \mathrm{R}$} & Between & 25.119 & 3 & 8.373 & 4.550 & 0.004 \\
\hline & & Within & 287.075 & 156 & 1.840 & & \\
\hline & & Total & 312.194 & 159 & & & \\
\hline \multirow{12}{*}{ Pattern } & \multirow{3}{*}{ (a) } & Between & 6.919 & 3 & 2.306 & 1.061 & 0.368 \\
\hline & & Within & 339.175 & 156 & 2.174 & & \\
\hline & & Total & 346.094 & 159 & & & \\
\hline & \multirow{3}{*}{ (b) } & Between & 31.969 & 3 & 10.656 & 5.263 & 0.002 \\
\hline & & Within & 315.875 & 156 & 2.025 & & \\
\hline & & Total & 347.844 & 159 & & & \\
\hline & \multirow{3}{*}{ (c) } & Between & 46.600 & 3 & 15.533 & 7.456 & 0.000 \\
\hline & & Within & 325.000 & 156 & 2.083 & & \\
\hline & & Total & 371.600 & 159 & & & \\
\hline & \multirow{3}{*}{ (d) } & Between & 2.619 & 3 & 0.873 & 0.380 & 0.768 \\
\hline & & Within & 358.625 & 156 & 2.299 & & \\
\hline & & Total & 361.244 & 159 & & & \\
\hline
\end{tabular}

In usage patterns, usage pattern (b) and (c) showed a significant difference in control comfort among the samples. Post hoc analysis showed two homogeneous subsets for each pattern. First, in pattern (b), the first subset was composed of the samples with a curvature of $6 R, 8 R$ and 10R, while the samples with a curvature of $4 R$ and $6 R$ constituted the second subset. Second, in pattern (c), the first subset was composed of the samples with a curvature of $8 R$ and 10R, while the samples with a curvature of $4 \mathrm{R}$ and $6 \mathrm{R}$ constituted the second subset.

\subsection{Stability}

Regarding stability, the effects of curvature and usage pattern were not significant (Table 9). Comparing them descriptively, the sample with a curvature of $8 \mathrm{R}$ scored the highest, followed by $6 \mathrm{R}, 4 \mathrm{R}$, and 10R (Table 3). However, the interaction effect between curvature and usage pattern was significant: $F(9,360)=2.071, p=0.031$. Therefore, a simple effect analysis was conducted separately according to the samples and usage patterns (Table 10).

Table 9. Results of four-way mixed ANOVA for stability (Test result of within subject effects).

\begin{tabular}{ccccccc}
\hline Source & $\begin{array}{c}\text { Sum of Squares } \\
\text { Type III }\end{array}$ & df & $\begin{array}{c}\text { Mean } \\
\text { Square }\end{array}$ & $\boldsymbol{F}$ & $p$ & $\eta_{p}^{2}$ \\
\hline Sample & 5.138 & 3 & 1.713 & 1.296 & 0.279 & 0.032 \\
Error (Sample) & 154.613 & 117 & 1.321 & & & 0.080 \\
Pattern & 14.063 & 3 & 4.688 & 2.307 & 0.056 \\
Error (Pattern) & 237.688 & 117 & 2.032 & & \multirow{2}{*}{0.050} \\
Sample $\times$ Pattern & 16.250 & 9 & 1.806 & 2.071 & 0.031 & 0.050 \\
Error (Sample $\times$ Pattern) & 306.000 & 351 & 0.872 & & & \\
\hline
\end{tabular}

In the case of samples, 10R showed a significant difference in grip comfort between the usage patterns: $F(3,159)=5.034, p=0.002$. Post hoc analysis showed two homogeneous subsets. The first subset comprised usage patterns of (a), (b), and (d), and the second subset comprised curvatures of (c). 
In the case of usage patterns, however, all patterns showed no significant differences in grip comfort between samples.

Table 10. Results of one-way ANOVA for stability by each sample and usage pattern.

\begin{tabular}{|c|c|c|c|c|c|c|c|}
\hline & Source & & $\begin{array}{c}\text { Sum of Squares } \\
\text { Type }\end{array}$ & df & $\begin{array}{l}\text { Mean } \\
\text { Square }\end{array}$ & $F$ & $p$ \\
\hline \multirow{12}{*}{ Sample } & \multirow{3}{*}{$4 \mathrm{R}$} & Between & 1.119 & 3 & 0.373 & 0.200 & 0.896 \\
\hline & & Within & 290.475 & 156 & 1.862 & & \\
\hline & & Total & 291.594 & 159 & & & \\
\hline & \multirow{3}{*}{$6 \mathrm{R}$} & Between & 1.250 & 3 & 0.417 & 0.270 & 0.847 \\
\hline & & Within & 240.750 & 156 & 1.543 & & \\
\hline & & Total & 242.000 & 159 & & & \\
\hline & \multirow{3}{*}{$8 \mathrm{R}$} & Between & 4.025 & 3 & 1.342 & 0.911 & 0.437 \\
\hline & & Within & 229.750 & 156 & 1.473 & & \\
\hline & & Total & 233.775 & 159 & & & \\
\hline & \multirow{3}{*}{$10 R$} & Between & 23.919 & 3 & 7.973 & 5.034 & 0.002 \\
\hline & & Within & 247.075 & 156 & 1.584 & & \\
\hline & & Total & 270.994 & 159 & & & \\
\hline \multirow{12}{*}{ Pattern } & \multirow{3}{*}{ (a) } & Between & 5.950 & 3 & 1.983 & 1.226 & 0.302 \\
\hline & & Within & 252.450 & 156 & 1.618 & & \\
\hline & & Total & 258.400 & 159 & & & \\
\hline & \multirow{3}{*}{ (b) } & Between & 4.100 & 3 & 1.367 & 0.953 & 0.417 \\
\hline & & Within & 223.800 & 156 & 1.435 & & \\
\hline & & Total & 227.900 & 159 & & & \\
\hline & \multirow{3}{*}{ (c) } & Between & 6.519 & 3 & 2.173 & 1.519 & 0.212 \\
\hline & & Within & 223.175 & 156 & 1.431 & & \\
\hline & & Total & 229.694 & 159 & & & \\
\hline & \multirow{3}{*}{ (d) } & Between & 4.819 & 3 & 1.606 & 0.812 & 0.489 \\
\hline & & Within & 308.625 & 156 & 1.978 & & \\
\hline & & Total & 313.444 & 159 & & & \\
\hline
\end{tabular}

\subsection{Front/Side Visibility}

Finally, for the visibility of the front and side, only the front visibility showed significant differences between the samples (Table 11). A post hoc analysis showed that there were three homogeneous subsets. The first subset comprised samples with curvatures of $8 \mathrm{R}$ and $10 \mathrm{R}$, while the other two samples were separated into two individual subsets: the second subset with the $6 \mathrm{R}$ curvature sample, and the third subset with the $4 \mathrm{R}$ curvature sample.

Table 11. Results of three-way mixed ANOVA for front/side visibility (Test result of within subject effects).

\begin{tabular}{cccccccc}
\hline $\begin{array}{c}\text { Evaluation } \\
\text { Factor }\end{array}$ & Source & $\begin{array}{c}\text { Sum of Squares } \\
\text { Type III }\end{array}$ & df & $\begin{array}{c}\text { Mean } \\
\text { Square }\end{array}$ & $\boldsymbol{F}$ & $p$ & $\eta_{p}^{2}$ \\
\hline Front & Sample & 163.419 & 3 & 54.473 & 62.281 & 0.000 & 0.615 \\
Visibility & Error (Sample) & 102.331 & 117 & 0.875 & & & \\
Side & Sample & 6.650 & 3 & 2.217 & 1.772 & 0.156 & 0.043 \\
Visibility & Error (Sample) & 146.350 & 117 & 1.251 & & & \\
\hline
\end{tabular}

\section{Discussion}

According to the ANOVA results, the samples with $4 \mathrm{R}$ and $6 \mathrm{R}$ were included in the third and second homogeneous subset for the front visibility, respectively. The control comfort for these two samples in use patterns (b) and (c) was included in the second homogeneous subset. In addition, the grip comfort for the sample with 10R in usage pattern (d) belonged to the second homogeneous subset. The sample with $8 \mathrm{R}$ was included in the first homogeneous subset for all analyses, while other samples were included in second or third homogeneous subset. There were some cases where other samples were evaluated better than the sample with $8 \mathrm{R}$, however, there were no statistically significant 
differences in those cases. Thus, it could be concluded that $8 \mathrm{R}$ is the optimal radius for the curvature of the edge screen in a smartphone.

In the case of grip comfort, only a sample with 10R showed a statistically significant effect of the usage pattern on grip comfort. As a result of the post hoc analysis, it was confirmed that usage patterns (a), (d) and (c) had significant differences in 10R. In particular, the value of grip comfort in usage pattern (d) was found to be the lowest. Grip comfort is the one of the most common patterns for people using smartphones. Through this study, when the side curvature was 10R, it was confirmed that the value grip comfort for the usage pattern related to holding the smartphone was the lowest. Therefore, it can be seen that designing the side curvature as 10R should be avoided.

In the case of control comfort, it was confirmed that there was a statistically significant difference in samples and interaction effect between the sample and usage pattern. Through post hoc analysis, it was confirmed that there was a significant difference between samples in usage pattern (b) and (c). As a result, to maximize control comfort in these usage patterns, it is necessary to design a side curvature of $8 \mathrm{R}$ or more. In addition, a sample with $10 \mathrm{R}$ showed a statistically significant effect of the usage pattern on control comfort. At this time, it was found that statistical significance between the two groups of usage pattern ((a), (d) and (b), (c)) appeared. Therefore, since various types of usage patterns appear in smartphones, designing the side curvature with 10R seems to be a non-universal design.

In terms of stability, a repeated two-way ANOVA result showed no significant effect of curvature and usage pattern. According to Eardley et al. [23], as the size of the smartphone gets bigger, security becomes lower. The samples used in this study had the same sized smartphone body, and there was a slight difference in size due to curvature. Therefore, as the size of the entire smartphone is almost the same, the curvature does not affect stability. In addition, Lee et al. [24] found that there was no significant difference between the NASA-TLX metrics according to bezel size in the smartphone. According to Lee et al. [24], the bezel was located at the bottom of the smartphone, and the curvature display was located on the right side in this study. Therefore, there is no difference in the subjective feeling of the user due to the size change of the smartphone by the bezel or the curvature display. However, the stability seems to be under the influence of grip comfort rather than control comfort because both stability and grip comfort showed similar results in terms of the evaluation of the curvature of the edge screen by usage pattern (Table 12). The front visibility was significantly under the effect of the curvature of the edge screen; a larger curvature derived a higher front visibility. This seems reasonable for providing better visibility as the area of the edge screen increases. However, the difference in front visibility between $8 \mathrm{R}$ and $10 \mathrm{R}$ according to the post hoc results was insignificant; thus, $8 \mathrm{R}$ is adequate to provide good front visibility. In addition, as with front visibility, the value of side visibility was evaluated to be high as the curvature increased. However, the difference in the evaluation was not statistically significant. This seemed to be caused by the fixed thickness of the samples, which hindered the effect of the area increment in edge screens; when viewed edge-on, there were no differences in visible area by different curvatures.

Although in this study, there were no statistically significant differences identified in sample and usage patterns for demographic variables such as gender and hand size, it has been reported in previous studies that demographic variables have a significant effect on smartphone design [17,24,25]. Balakrishnan and Paul [25] showed that the subjective satisfaction increases as the hand size of male and female subjects decreases when people text on mobile phones. Lin [18] conducted research that small-handed people experience increased subjective fatigue as the size of their smartphones increases, while those with larger hands show the opposite result. However, there was no significant difference in the results of independent $t$-tests between the small-hand and large-hand groups in the study. According to the research of Lee et al. [6], there was no statistically significant difference between hand size and perceived discomfort.

Since most of the previous studies were conducted to understand the subjective feeling of the front display of the smartphone, it can be inferred from this study that there is a difference in the side display of the smartphone. Considering the reason for the research results, Lin [18] performed a study 
to determine the degree of subjective comfort caused by the size of the smartphone relative to the size of the hand, with a difference of 0.5 inches between samples. In addition, the difference in the samples used in Xiong and Muraki [26], who compared the area of thumb movement coverage in smartphones according to the size of the smartphone, was approximately $10 \mathrm{~mm}$. From this point of view, the difference in sample width due to the curvature used in the study was less than $5 \mathrm{~mm}$ at maximum, because only the width of the bezel on the right side of the smartphone was the object of adjustment. Therefore, it is expected that the difference in width due to the curvature should be set to at least $10 \mathrm{~mm}$ in future studies.

Table 12. Results of subjective evaluation for grip comfort, control comfort and stability.

\begin{tabular}{clcccccccc}
\hline \multirow{2}{*}{$\begin{array}{c}\text { Evaluation } \\
\text { Factor }\end{array}$} & \multirow{2}{*}{ Pattern } & \multicolumn{2}{c}{ 4R } & \multicolumn{2}{c}{ 6R } & \multicolumn{2}{c}{ 8R } & \multicolumn{2}{c}{ 10R } \\
\cline { 2 - 9 } & & Mean & SD & Mean & SD & Mean & SD & Mean & SD \\
\hline \multirow{3}{*}{ Grip } & Pattern (a) & 4.700 & 1.572 & 4.700 & 1.265 & 4.800 & 1.305 & 4.450 & 1.431 \\
Comfort & Pattern (b) & 4.600 & 1.297 & 4.950 & 0.932 & 5.075 & 1.095 & 4.750 & 1.296 \\
& Pattern (c) & 4.625 & 1.531 & 4.675 & 1.269 & 4.975 & 1.230 & 5.200 & 1.224 \\
& Pattern (d) & 4.700 & 1.324 & 4.875 & 1.488 & 4.775 & 1.561 & 4.175 & 1.412 \\
\hline \multirow{3}{*}{ Control } & Pattern (a) & 4.175 & 1.662 & 4.250 & 1.410 & 4.700 & 1.471 & 4.250 & 1.335 \\
Comfort & Pattern (b) & 3.850 & 1.578 & 4.450 & 1.358 & 4.775 & 1.441 & 5.050 & 1.300 \\
& Pattern (c) & 3.750 & 1.645 & 4.100 & 1.499 & 5.000 & 1.281 & 4.950 & 1.319 \\
& Pattern (d) & 4.350 & 1.610 & 4.525 & 1.450 & 4.425 & 1.534 & 4.175 & 1.466 \\
\hline \multirow{5}{*}{ Stability } & Pattern (a) & 5.000 & 1.450 & 4.950 & 1.218 & 5.075 & 1.095 & 4.575 & 1.299 \\
& Pattern (b) & 4.900 & 1.277 & 5.150 & 1.075 & 5.100 & 1.194 & 4.750 & 1.235 \\
& Pattern (c) & 4.950 & 1.377 & 4.975 & 1.143 & 5.200 & 1.091 & 5.450 & 1.154 \\
& Pattern (d) & 4.775 & 1.349 & 4.925 & 1.492 & 4.775 & 1.441 & 4.450 & 1.339 \\
\hline
\end{tabular}

\section{Conclusions}

Overall, this study investigated the effect of the curvature of the edge screen on users' grip comfort, control comfort, stability, and visibility, based on subjective evaluation experiments. Especially, four representative usage patterns were defined and evaluated to investigate the interaction effect of curvature and usage patterns for grip comfort, control comfort, and stability. As a result, $8 \mathrm{R}$ was the most appropriate radius of curvature for edge screens when the overall results were considered. The results showed that the effect of curvature on grip and control comfort varies by usage pattern.

This study can be used as fundamental research to understand the subjective feeling in smartphones with a curvature display, which is being developed recently. However, this study has limitations based on surveys without using quantitative indices such as electromyography (EMG). In a future study, these quantitative indices to determine the relationship between subjective feelings and muscle fatigue due to changes in curvature of the screen can be conducted. In addition, it is expected that it will be possible to study the optimum curvature of display for various types of hands by considering not only the length of the hand but also the hand measurements such as the circumference and the finger.

Author Contributions: All authors have substantially contributed to the conceptualization, methodology, formal analysis, investigation, resources, and data curation. Y.L., J.H.L., Y.M.K., and W.K. contributed to the writing original draft and editing. Y.L., and J.H.L. contributed to the data collection and validation. W.K., and M.H.Y. contributed to the project administration, supervision, and funding acquisition. All authors have read and agreed to the published version of the manuscript.

Funding: This research was supported by the National Research Foundation of Korea (NRF) grant funded by the Korea government (MSIT: Ministry of Science and ICT) (No. 2020R1G1A1003384).

Acknowledgments: The authors thank the administrative support from the Institute for Industrial Systems Innovation of Seoul National University. This research was supported by the BK21 Plus Program (Centre for Sustainable and Innovative Industrial Systems) funded by the Ministry of Education, South Korea. (No. 21A20130012638).

Conflicts of Interest: The authors declare no conflict of interest. 


\section{References}

1. Xiong, J.; Muraki, S. An ergonomics study of thumb movements on smartphone touch screen. Ergonomics 2014, 57, 943-955. [CrossRef]

2. Wang, J.; Wang, H.-Z.; Gaskin, J.; Wang, L. The role of stress and motivation in problematic smartphone use among college students. Comput. Hum. Behav. 2015, 53, 181-188. [CrossRef]

3. Liu, C. Worldwide internet and mobile users: Emarketer's updated estimates for 2015. eMarketer Tech. Rep. 2015.

4. Vuori, T.O.; Huy, Q.N. Distributed attention and shared emotions in the innovation process: How Nokia lost the smartphone battle. Adm. Sci. Q. 2016, 61, 9-51. [CrossRef]

5. Pereira, A.; Miller, T.; Huang, Y.-M.; Odell, D.; Rempel, D. Holding a tablet computer with one hand: Effect of tablet design features on biomechanics and subjective usability among users with small hands. Ergonomics 2013, 56, 1363-1375. [CrossRef]

6. Lee, S.; Kyung, G.; Lee, J.; Moon, S.K.; Park, K.J. Grasp and index finger reach zone during one-handed smartphone rear interaction: Effects of task type, phone width and hand length. Ergonomics 2016, 59, 1462-1472. [CrossRef]

7. Sung, K.; Cho, J.; Freivalds, A. Effects of grip span in one-handed thumb interaction with a smartphone. Proc. Hum. Factors Ergon. Soc. Annu. Meet. 2016, 60, 1048-1052. [CrossRef]

8. Chowdhury, A.; Kanetkar, M. Determination of Most Preferred Mobile Phone Size Based on Hand Anthropometry and Mobile Handiness. In Advances in Theory and Practice of Computational Mechanics; Springer Science and Business Media LLC: Singapore, 2017; Volume 65, pp. 195-204.

9. Lee, Y.; Lee, J.H.; Kim, Y.M.; Lee, J.; Kwon, S.; Sim, H.; Yun, M.H. The Effects of Curvature of Edge Screen on Subjective Feelings in Smartphone Usage. Proc. Hum. Factors Ergon. Soc. Annu. Meet. 2017, 61, 1269-1270. [CrossRef]

10. Ling, C.; Hwang, W.; Salvendy, G. A survey of what customers want in a cell phone design. Behav. Inf. Technol. 2007, 26, 149-163. [CrossRef]

11. Ahn, S.H.; Kwon, S.; Bahn, S.; Yun, M.H.; Yu, W. Effects of Grip Curvature and Hand Anthropometry for the Unimanual Operation of Touchscreen Handheld Devices. Hum. Factors Ergon. Manuf. 2016, 26, 367-380. [CrossRef]

12. Kwon, S.; Bahn, S.; Ahn, S.H.; Lee, Y.; Yun, M.H. A study on the relationships among hand muscles and form factors of large-screen curved mobile devices. Int. J. Ind. Ergon. 2016, 56, 17-24. [CrossRef]

13. Yi, J.; Park, S.; Im, J.; Jeon, S.; Kyung, G. Effects of display curvature and hand length on smartphone usability. Proc. Hum. Factors Ergon. Soc. Annu. Meet. 2017, 61, 1054-1057. [CrossRef]

14. Karlson, A.K.; Bederson, B.B.; Contreras-Vidal, J.L. Understanding One-Handed Use of Mobile Devices. In Handbook of Research on User Interface Design and Evaluation for Mobile Technology; IGI Global: Hershey, PA, USA, 2008; pp. 86-101.

15. Le, H.V.; Bader, P.; Kosch, T.; Henze, N. Investigating Screen Shifting Techniques to Improve One-Handed Smartphone Usage. In Proceedings of the 9th Nordic Conference on Human-Computer Interaction-NordiCHI '16, Gothenburg Sweden, 23-27 October 2016; pp. 1-10.

16. Zhang, Y.; Ou, B.; Ding, Q.; Yang, Y. Touch Behavior Analysis for Large Screen Smartphones. Proc. Hum. Factors Ergon. Soc. Annu. Meet. 2015, 59, 1433-1437. [CrossRef]

17. Balakrishnan, V.; Yeow, P. Hand Anthropometry and SMS Satisfaction. J. Appl. Sci. 2008, 8, 816-822. [CrossRef]

18. Lin, Y.-C. The Relationship between Touchscreen Sizes of Smartphones and Hand Dimensions. In Applications of Evolutionary Computation; Springer Science and Business Media LLC: Berlin/Heidelberg, Germany, 2013; Volume 8011, pp. 643-650.

19. Park, D.; Park, S.; Kim, W.; Rhiu, I.; Yun, M.H. A comparative study on subjective feeling of engine acceleration sound by automobile types. Int. J. Ind. Ergon. 2019, 74, 102843. [CrossRef]

20. Moon, S.; Park, S.; Park, D.; Kim, W.; Yun, M.H.; Park, D. A Study on Affective Dimensions to Engine Acceleration Sound Quality Using Acoustic Parameters. Appl. Sci. 2019, 9, 604. [CrossRef]

21. Kim, W.; Park, D.; Kim, Y.M.; Ryu, T.; Yun, M.H. Sound quality evaluation for vehicle door opening sound using psychoacoustic parameters. J. Eng. Res 2018, 6, 176-190. 
22. Kim, W.; Lee, Y.; Lee, J.H.; Shin, G.W.; Yun, M.H. A comparative study on designer and customer preference models of leather for vehicle. Int. J. Ind. Ergon. 2018, 65, 110-121. [CrossRef]

23. Eardley, R.; Roudaut, A.; Gill, S.; Thompson, S. Understanding Grip Shifts: How Form Factors Impact Hand Movements on Mobile Phones. In Proceedings of the 2017 CHI Conference on Human Factors in Computing Systems, Denver, CO, USA, 6-11 May 2017; pp. 4680-4691.

24. Lee, S.C.; Cha, M.C.; Hwangbo, H.; Mo, S.; Ji, Y.G. Smartphone form factors: Effects of width and bottom bezel on touch performance, workload, and physical demand. Appl. Ergon. 2018, 67, 142-150. [CrossRef]

25. Balakrishnan, V.; Yeow, H.P. Hand-size variations effect on mobile phone texting satisfaction. System 2007, 6, 8-10.

26. Xiong, J.; Muraki, S. Effects of age, thumb length and screen size on thumb movement coverage on smartphone touchscreens. Int. J. Ind. Ergon. 2016, 53, 140-148. [CrossRef]

(C) 2020 by the authors. Licensee MDPI, Basel, Switzerland. This article is an open access article distributed under the terms and conditions of the Creative Commons Attribution (CC BY) license (http://creativecommons.org/licenses/by/4.0/). 